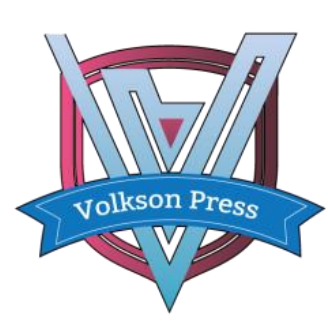

Contents List available at VOLKSON PRESS

New Materials and Intelligent Manufacturing (NMIM)

DOI : http://doi.org/10.26480/icnmim.01.2018.265.269

Journal Homepage : https://topicsonchemeng.org.my/

ISBN: 978-1-948012-12-6

\title{
APPLICATION OF AHP-ENTROPY METHOD AND LSSVM IN THE ASSESSMENT AND FORECASTING OF TRANSFORMER OPERATING STATUS
}

\author{
Niu Guocheng ${ }^{1,3}$, Hu Zhen $^{1 *}$, Hu Dongmei ${ }^{2}$ \\ ${ }^{1}$ College of electronic information engineering, Changchun University Science and Technology, Weixing Street, Changchun, China. \\ ${ }^{2}$ College of Electronic and information Engineering, Beihua University, \\ Xinshan Street, Jilin, China. \\ *Corresponding Author Email: huzhen21st@sina.com
}

This is an open access article distributed under the Creative Commons Attribution License, which permits unrestricted use, distribution, and reproduction in any medium, provided the original work is properly cited

\section{ARTICLE DETAILS}

Article History:

Received 26 June 2018

Accepted 2 july 2018

Available online 1 August 2018

\begin{abstract}
In order to meet the needs of fault troubleshooting, maintenance decision and on-line prediction, the method of the transformer health index based on AHP-entropy is proposed. The cross complex matter elements are established between the transformer health index and dissolved gases and typical faults. The subjective and objective weights affecting the transformer health index are determined by Analytic Hierarchy Process (AHP) and information entropy respectively, and the transformer health index is calculated quantitatively by matter element-maximum information entropy, the calculation is used as the predicting information, and the Least Squares Support Vector Machine (LSSVM) is used to predict the transformer operation status. the scheme provides a new feasible method to evaluate, quantify and forecast the transformer operation status.
\end{abstract}

\section{KEYWORDS}

Transfomer, Health Index, Analytic Hierarchy Process (Ahp), Complex Matter Element, Support Vector Regression (Lssvm).

\section{INTRODUCTION}

As a hub equipment for power systems, the operation status of large-scale oil-impregnated power transformers is directly related to the safety and stability of the power grid, and the sudden failure of transformers will bring huge economic losses [1, 2]. During the operation of the oil immersed transformer, there will be overheating or discharging faults, which will produce hydrogen gas such as $\mathrm{CH}_{4}, \mathrm{C}_{2} \mathrm{H}_{2}, \mathrm{C}_{2} \mathrm{H}_{4}, \mathrm{C}_{2} \mathrm{H}_{6}, \mathrm{H}_{2}[3,4]$. The dissolved gas analysis (DGA) technology in oil can detect the dissolved gas in the oil without interrupting maintenance. It can reduce the time of transformer interruption maintenance and is beneficial to the development of transformer status monitoring technology [5]. The classification, diagnosis and evaluation of transformer faults can be realized by the use of dissolved gas in oil. At present, the research on transformers mainly focuses on the classification, diagnosis and assessment of their faults. In the literature, ABB company realizes the monitoring of power transformer operation state, fault classification, operation state analysis and confirmation, and evaluation of operation risk and life. In the literature, the fuzzy comprehensive evaluation method is used to evaluate the health state and GIS [6-9]. In the literature $[9,10]$. The artificial neural network and information fusion technology are used to evaluate the transformer operation status. The existing methods have greatly promoted the research of the equipment status assessment, but there is also a problem which is not comprehensive and has a high dependence on the knowledge of experts [11]. However, there are few study on the health status prediction of transformers.

With the development of data mining technology, it is possible to accurately evaluate and predict the operation state of transformers. The health status of transformers is quantitatively calculated from both subjective and objective aspects based on gases data in transformer oil. According to the historical health index data, the support vector machine with parameters optimization is used to predict the running state of the transformer, and the scientific management of the transformer from regular maintenance to state maintenance is carried out.

\section{ENTROPY AND COMBINED WEIGHT EVALUATION MODEL}

\subsection{Subjective weight calculation}

Analytic Hierarchy Process (AHP) is a multi-objective decision analysis method, which combines qualitative and quantitative analysis, and is proposed by T. L. Saaty of Pittsburgh University in the United States [12]. It introduces the experters' experience into different levels and quantifies some complex and difficult decision problems. Calculation, the process is simple and easy. In this paper, AHP is used to calculate the subjective weights of health index. The main steps are as follows:

2.1.1 Establishment of composite matter element hierarchical structure model

In order to study the subjective factors affecting the operating state of the transformer, the AHP is used to establish the complex element model of the transformer faults, which reflects the mutual influence between the gas and the common faults.

The model is divided into three layers, and the decision layer $\mathrm{C}$ is " $\mathrm{H}_{2}\left(\mathrm{C}_{1}\right)$, $\mathrm{CH}_{4}\left(\mathrm{C}_{2}\right), \mathrm{C}_{2} \mathrm{H}_{6}\left(\mathrm{C}_{3}\right), \mathrm{C}_{2} \mathrm{H}_{4}\left(\mathrm{C}_{4}\right), \mathrm{C}_{2} \mathrm{H}_{2}\left(\mathrm{C}_{5}\right), \sum \mathrm{CH}\left(\mathrm{C}_{6}\right)$. The criterion layer B is six transformer faults. "General overheating $\left(\mathrm{B}_{1}\right)$, severe overheat $\left(\mathrm{B}_{2}\right)$, partial discharge $\left(B_{3}\right)$, spark discharge $\left(B_{4}\right)$, arc discharge $\left(B_{5}\right)$, overheating and arc discharge (B6)", the target level A is the transformers' health index.

\subsubsection{Construction of Judgment Matrix}

Establish the AHP Weight Matrices for the target layer A and the criterion layer B. The square root method is used to calculate the maximum eigenvalue root $\lambda_{\max }$ of the judgement matrix. Its corresponding normalized eigenvector $W=\left(\omega_{1}, \omega_{2} \cdots \omega_{n}\right)^{T}$, and $A W=\lambda_{\max } W$. 


\subsubsection{Consistency Test}

a. Calculating the consistency index C.I.: C.I. $=\left(\lambda_{\max }-n\right) /(n-1)$. Where, $\mathrm{n}$ is the order of judgment matrix.

b. Calculating the average random consistency index $R I$.

c. Calculating the conformance ratio C.R.: C.R. $=C I / R I$. If $C R \leq 0.1$, it is considered that the consistency of the judgment matrix is acceptable.

\subsubsection{Calculation of objective weight}

The weight of each decision is calculated as:

$$
\omega^{\prime}=W_{C} \times W_{A}
$$

Where, $W_{C}=\left[\omega_{C 1}, \omega_{C 2}, \cdots \omega_{C n}\right.$, $]$ is the feature vectors of each decision parameters, $W_{A}=\left[\omega_{A 1}, \omega_{A 2}, \cdots \omega_{A n}\right]^{T}$ is the feature vectors of the target layers.

\subsection{Subjective weight calculation}

Information entropy is used to measure the uncertainty of random variables and can be used to solve the problem of information quantity measurement [12]. The entropy method is used to eliminate the human interference in calculating the weights of each index when applying the AHP method, so that the evaluation results are closer to reality.

\subsubsection{Establishment of the stereoscopic cross compound matter element}

The detection data of the transformer oil at different times is used as $\mathrm{m}$ evaluation schemes, and $\mathrm{n}$ is the parameters related decision making. Thus, the n-Dimensional Compound Element of the m Stereoscopic Cross Schemes of the Evaluation Index is:

$$
\left.R_{m n}=\mid \begin{array}{lllll} 
& M_{1} & M_{2} & \cdots & M_{n} \\
C_{1} & x_{11} & x_{21} & \cdots & x_{m 1} \\
C_{2} & x_{12} & x_{22} & \cdots & x_{m 2} \\
\vdots & \vdots & \vdots & \ddots & \vdots \\
C_{n} & x_{1 n} & x_{2 n} & \cdots & x_{m n}
\end{array}\right\rfloor
$$

$M_{i}$ is the $i$-th stereoscopic cross scheme to be evaluated; $C_{j}$ is the $j$ th evaluation index of the stereoscopic cross scheme; $x_{i j}$ is the corresponding $j$-th index value of the $i$-th scheme to be evaluated.

\subsubsection{The Standardization of the Stereoscopic Cross Matter-Element}

In the calculation, it is necessary to standardize the evaluation index. The formula (3) will be used to standardize the one who has the propelling effect on the evaluation index. The formula (4) will be used to standardize the one who can weaken the evaluation index

$$
\begin{aligned}
& \delta_{i j}=\left(x_{i j}-\min _{1 \leq i \leq n} x_{i j}\right) /\left(\max _{1 \leq i \leq n} x_{i j}-x_{i j}\right) \\
& \text { (3) } \\
& \delta_{i j}=\left(\max _{1 \leq i \leq n} x_{i j}-x_{i j}\right) /\left(\max _{1 \leq i \leq n} x_{i j} \quad \min x_{i j}\right) \\
& \left(i=1,2, \cdots, n ; j \in J^{-}\right)
\end{aligned}
$$

\subsubsection{Subjective weight calculation}

In the evaluation factors system, the importance of each factor to the objectives and functions of the system is expressed by weight, and the correlation entropy method is used to determine it. The correlation function uses maximum entropy theory $\delta_{0, j}=\max _{1 \leq i \leq n} \delta_{i, j}, j=1,2, \cdots, n$, then the correlation function of the $j_{\text {-th item index }} C_{j}$ of the compound matter element is:

$$
\zeta_{i j}=\frac{\min _{i} \min _{j}\left|\delta_{i j}-y_{j}\right|+0.5 \max _{i} \max _{j}\left|\delta_{i j}-y_{j}\right|}{\left|\delta_{i j}-y_{j}\right|+0.5 \max _{i} \max _{j}\left|\delta_{i j}-y_{j}\right|}
$$

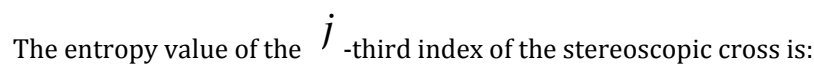

$$
F_{j}=K \sum_{i}^{m} f_{i, j} \ln f_{i, j}
$$

$$
\text { Where, } K=-\left(H_{\max }\right)=-(\ln n)^{-1} \text {, }
$$

$$
f_{i, j}=\zeta_{i, j} / \sum_{i=1}^{m} \zeta_{i, j}, j=1,2, \cdots, m ; F_{j} \in\lfloor 0,1\rfloor \text {. The weight }
$$

coefficient of the index is $\omega^{\prime \prime}$ as follows:

$$
\omega^{\prime \prime}=e_{j} / \sum_{j=1}^{n} e_{j}
$$

The deviation degree of entropy value is :

$$
e_{j}=1-F_{j}
$$

\subsection{Joint weight of information entropy}

The subjective weight calculated by AHP method is $\omega^{\prime}$, the objective weight calculated by entropy method is $\omega^{\prime \prime}$. Considering the shortcomings of subjective weight and objective weight, the compound matter-element entropy of the photoacoustic spectroscopy is used. The ultimate weight is the joint weight of two weights.

$$
\omega_{i}=\omega_{i}^{\prime} \omega_{i}^{\prime \prime} / \sum_{i=1}^{n} \omega_{i}^{\prime} \omega_{i}^{\prime \prime}
$$

\subsection{Calculation and analysis of the health index}

The experimental data is derived from the $110 \mathrm{KV}$ distribution transformer of the Jilin Songhua River thermal power plant. The photoacoustic spectroscopy is used to detect the sample data of the in-transformer oil in evry week during the operation of the transformer. 48 sets of experimental gases $\left(\mathrm{CH}_{4}, \mathrm{C}_{2} \mathrm{H}_{2}, \mathrm{C}_{2} \mathrm{H}_{4}, \mathrm{C}_{2} \mathrm{H}_{6}, \mathrm{H}_{2}\right.$, total hydrogen gas) samples are collected [13].

According to the relevance between different levels, the AHP weight matrixes of target layer matrix $A$ and index layer matrix $B_{1}, B_{2}, B_{3}, B_{4}, B_{5}$ and $B_{6}$ are constructed by 1-9 scale method [14]. The values of each element in the matrix is determined by the current guidelines for analysis and determination of dissolved gases in transformer oil (DL/T722-2000) and the modified three ratio method.

The average random consistency index obtained after 1000 calculations is shown in Table 1, the fifth order value is 1.12 .

Table 1: Consistency verification each parameter value

\begin{tabular}{|lllll|}
\hline $\begin{array}{l}\text { Judgment } \\
\text { matrix }\end{array}$ & $\lambda_{\text {max }}$ & $\mathrm{CI}$ & $\mathrm{RI}$ & $\mathrm{CR}$ \\
\hline $\mathrm{A}$ & 6.873 & 0.017 & 1.12 & 0.016 \\
$\mathrm{~B}_{1}$ & 4.033 & 0.011 & 1.12 & 0.009 \\
$\mathrm{~B}_{2}$ & 5.079 & 0.002 & 1.12 & 0.002 \\
$\mathrm{~B}_{3}$ & 3.004 & 0.002 & 1.12 & 0.002 \\
$\mathrm{~B}_{4}$ & 3.136 & 0.068 & 1.12 & 0.061 \\
$\mathrm{~B}_{5}$ & 4.046 & 0.015 & 1.12 & 0.014 \\
$\mathrm{~B}_{6}$ & 4.027 & 0.009 & 1.12 & 0.008 \\
\hline
\end{tabular}

From table 1, it is known that the CR values are much less than 0.1 , so the discriminant matrices are all satisfactory. After the hierarchical single sorting and the hierarchical total sorting of the matrix, the subjective weight $\omega^{\prime}$ is shown in Table 2. 
Topics in Chemical \& Material Engineering (TCME) 1(1) (2018) 265-269

Table 2: AHP weights of evaluation Indexes

\begin{tabular}{|lllllllll}
\hline & Criterion & B1 & B2 & B3 & B4 & B5 & B6 \\
Decision & Weight & 0.053 & 0.153 & 0.153 & 0.16 & 0.213 & 0.267 \\
\hline C1 & & 0.455 & 0.157 & 0.309 & 0 & 0 & 0 \\
C2 & 0.257 & 0.314 & 0 & 0.188 & 0 & 0.096 \\
C3 & 0.118 & 0.057 & 0 & 0.263 & 0.358 & 0.092 \\
C4 & 0 & 0.157 & 0.582 & 0.547 & 0.23 & 0.135 \\
C5 & & 0 & 0.109 & 0 & 0.11 & 0.107 \\
C6 & & 0.171 & 0.314 & 0 & 0 & 0.302 & 0.47 \\
\hline
\end{tabular}

Table 3: Entropy weights of evaluation Indexes

\begin{tabular}{|lcll|}
\hline $\begin{array}{l}\text { evaluation } \\
\text { indicators }\end{array}$ & $F_{j}$ & $e_{j}$ & $\omega^{\prime \prime}$ \\
\hline C1 & 0.636 & 0.364 & 0.168 \\
C2 & 0.638 & 0.362 & 0.168 \\
C3 & 0.638 & 0.362 & 0.163 \\
C4 & 0.648 & 0.352 & 0.172 \\
C5 & 0.648 & 0.352 & 0.162 \\
C6 & 0.613 & 0.387 & 0.169 \\
\hline
\end{tabular}

Table 4: Complex weights of evaluation Indexes

\begin{tabular}{|llll|}
\hline evaluation indicators & $\omega^{\prime}$ & $\omega^{\prime \prime}$ & $\omega$ \\
\hline $\mathrm{C}_{1}$ & 0.096 & 0.167 & 0.097 \\
$\mathrm{C}_{2}$ & 0.092 & 0.166 & 0.091 \\
$\mathrm{C}_{3}$ & 0.170 & 0.166 & 0.168 \\
$\mathrm{C}_{4}$ & 0.327 & 0.162 & 0.316 \\
$\mathrm{C}_{5}$ & 0.069 & 0.162 & 0.067 \\
$\mathrm{C}_{6}$ & 0.247 & 0.178 & 0.262 \\
\hline
\end{tabular}

The entropy value is used to reflect the disordered degree of the parameters, so, the entropy method is used to quantitatively analyze the health index of transformers. For a certain indicator, the information entropy is:

$$
\begin{aligned}
& H=-\sum_{J=1}^{N} P\left(\omega_{j} \delta_{i j}\right) \ln P\left(\omega_{j} \delta_{i j}\right) \\
& P\left(\omega_{j} \delta_{i j}\right)=\omega_{j} \delta_{i j}\left[\sum_{j=1}^{n} \omega_{j} \delta_{i j}\right]^{-1} \\
& i=1,2 \cdots m, \quad j=1,2 \cdots n, \omega_{j} \text { Represents the weight }
\end{aligned}
$$

of the impact of decision-making on the health of the target.

By formula (10) and (11), the health index of each month of the transformer is $H_{-} \omega^{\prime \prime}$ (the health index under the objective weight) and the $H_{-} \omega$ (health index under the compound weight). The ranking results

\begin{tabular}{|c|c|c|c|c|c|c|c|c|c|c|c|c|}
\hline $\begin{array}{ll}\text { health } & \text { index } \\
\text { ranking } & \end{array}$ & NO.1 & NO.2 & NO.3 & NO.4 & NO.5 & N0.6 & NO.7 & NO.8 & N0.9 & N0.10 & N0.11 & NO.12 \\
\hline Index_$\omega^{\prime \prime}$ & 1.69 & 1.7 & 1.7 & 1.701 & 1.702 & 1.704 & 1.704 & 1.705 & 1.706 & 1.706 & 1.747 & 1.77 \\
\hline Index_ $\omega$ & 1.535 & 1.56 & 1.567 & 1.58 & 1.583 & 1.59 & 1.599 & 1.606 & 1.61 & 1.644 & 1.669 & 1.681 \\
\hline
\end{tabular}
are shown in Table 5.

Table 5: The calculation results of different weight health index

\section{HEALTH INDEX PREDICTION OF PRODUCTION CONDITION}

\subsection{Forecast data samples}

The dissolved gas in the weekly transformer oil per month are measured by photoacoustic spectroscopy. The health index of the transformer obtained by Formula (10) and (11) are the original data samples. The health index of three weeks in a month are the training set, and the last week's health index are the testing set.

\subsection{Predictive modelling}

In order to realize the prediction of transformer operation status, the prediction model of transformer's historical health index is built in Matlab 7.11.0. LSSVM is used. The optimal combination of the kernel function parameters $\sigma^{2}$ and the super parameters $\gamma_{\text {is determined by the grid- }}$ search with the cross validation, Finally, the estimation function is

$f(x)=\sum_{i=1}^{l} \alpha_{i} K\left(x, x_{i}\right)+b$

$\left.K\left(x, x_{i}\right)=\exp \left(-\left\|x-x_{i}\right\|^{2} / 2 \sigma^{2}\right), \sigma>0\right)$ is a kernel function,

$\alpha_{i}$ is a Lagrange multiplier, $\mathrm{b}$ is a threshold, and it is a constant.

In order to demonstrate the superiority of the method, the support vector machine (SVM) is used, the kernel function is the same to above, using genetic algorithm (GA), grid search (grid-search) and particle swarm optimization (PSO) to optimize the parameters (the penalty parameter $c$, the span coefficient $g$ of the RBF function). The training simulation curves are shown in Figure 1, and the testing simulation curves are shown in Figure 2.

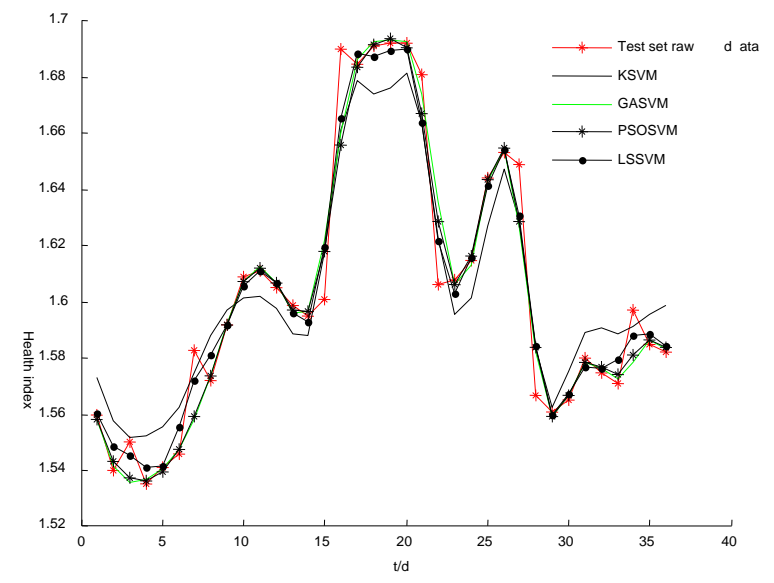

Figure 1: Training simulation curves 


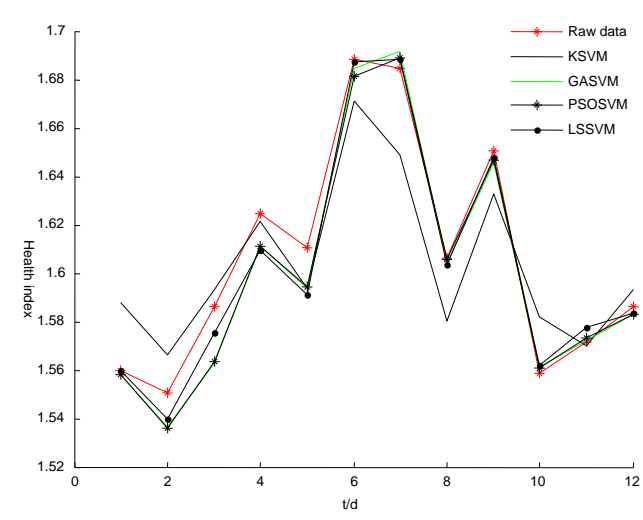

\subsection{Performance Comparison of Modelling Methods}

The evaluation indicators are shown in table $6,(c$ and $g)$ and $\left(\sigma^{2}\right.$ and $\gamma$ ) are the optimal parameters. Train-MSE and Train-R are the errors and correlation coefficients in fitting [15]. Test-MSE and Test- $\mathrm{R}$ are the error and correlation coefficient in testing. $\mathrm{T}$ is the simulation run time.

Figure 2: Testing set simulation curves

Table 6: Performances comparison of four methods

\begin{tabular}{|lllll|}
\hline \multirow{2}{*}{ evaluation indicators } & \multicolumn{2}{l}{ SVM } & & LSSVM \\
\cline { 2 - 5 } & $\mathrm{KC}$ & $\mathrm{GA}$ & $\mathrm{PSO}$ & $\mathrm{KC}$ \\
\hline \multirow{2}{*}{ optimal parameters } & $\mathrm{c}=0.0625$ & $\mathrm{c}=2.084$ & $\mathrm{c}=1.5492$ & $\sigma^{2}=0.03$ \\
TRMSE & $\mathrm{g}=0.25$ & $\mathrm{~g}=156.87$ & $\mathrm{~g}=173.5$ & $\gamma=9.1269$ \\
TRC & 0.6564 & 0.0686 & 0.0653 & 0.0594 \\
TEMSE & $93.86 \%$ & $98.46 \%$ & $98.51 \%$ & $98.61 \%$ \\
TEC & 0.6525 & 0.0617 & 0.0625 & 0.0616 \\
T $(\mathrm{s})$ & $97.35 \%$ & $97.4 \%$ & $97.66 \%$ & $97.81 \%$ \\
\hline
\end{tabular}

It is known from the table 8 and the Figure 1 and Figure 2 that the prediction effect of LSSVM optimized by cross validation, is better, when $\sigma^{2}=0.03, \gamma=9.1269$, the training error and the correlation coefficient are $0.0594 / 98.61 \%$, and the prediction error and the correlation coefficient are $0.00616 / 97.81 \%$, and the running time is less $0.01 \mathrm{~s}$, and it can meet the demand of actual application of the online prediction.

\section{CONCLUSION}

In this paper, the evaluation and prediction of the operation status of the transformer are studied. First, the subjective weight of the transformer index are calculated by AHP. Secondly, the objective weight of the transformer index are determined by the information entropy method, and then the joint weight are determined, and the composite element maximum entropy theory is used to calculate the transformer index. At last, the health index of the transformer is used as the prediction set and the verification set, and the prediction model of the transformer operation status is established by the least square support vector machine. In this way, the quantitative analysis of the transformer operation status can be realized, and the operation status of the transformer can be predicted, so as to achieve the better transformer. It provides theoretical and data support for troubleshooting, maintenance decision-making and online prediction.

\section{REFERENCES}

[1] Zhang, Y.Y., Jiao, J., Wang, K. 2018. Power transformer Fault Diagnosis based on Support Vector Machine Optimized by Imperialist Competitive Algorithm [J]. Electric Power automation Equipment, 38 (1), 99-104.

[2] Li, Q.Q., Li, S.M., Si, W. 2017. Analysis of the Key Problem About Insulation Condition Assessment of Oil-paper in Power transformers Based on Partial Discharge [J]. High Voltage Engineering, 43 (8), 25582565.

[3] Lahmiri, S., Boukadoum, M. 2014. Biomedical image denoising using variational mode decomposition [C]//Biomedical Circuits and Systems Conference. BioCAS. Lausanne, IEEE, 340.

[4] Ye, H.M., Xiao, Z.D. 2014. Application of multi-sensor information fusion technology to transformer fault diagnosis [J]. Transformer, 51 (9), 60.
[5] Wang, K., Li, J.Z., Zhang, S.Q. 2016. New features derived from dissolved gas analysis for fault diagnosis of power Transformers [J]. Proceedings of the CSEE, 36 (23), 6570-6578.

[6] Karen, S., Shakeel, M., Paul. 2014. Picture of health an integrated approach to asset health management [J]. Asset Management \& Maintenance Journal, 27 (4), 31-34.

[7] Liao, R.J., Wang, Q., Luo, S.J. 2008. Condition assessment model for power transformer in service based on fuzzy synthetic evaluation [J]. Automation of Electric Power Systems, 32 (3), 70-75.

[8] Chen, P.Y. 2013. Gas insulated switch gear running state comprehensive evaluation based on analytic hierarchy process of fuzzy theory [D]. Beijing : North China Electric Power University.

[9] Chen, F.G., Zhou, B.X., Zeng, L.Y. 2013. State Evaluation model of transformer operation based on multi-information fusion [J]. Proceedings of the CSU-EPSA, 25 (4), 140-144.

[10] Ruan, L., Xie, Q.J., Gao, S.Y. 2014. Application of artificial neural network and information fusion technology in power transformer condition assessment [J]. High Voltage Engineering, 40 (3), 822-828.

[11] Li, Z.Z., Xie, Z.C., Xiong, W.H. 2016. Rotor fault detection based on SVD filtering and APES algorithm for asynchronous motor Electric Power automation Equipment, 36 (8), 137-142.

[12] Chen, W.B., Gong, D.S. 2012. Informatization vendor evaluation model based on AHP entropy method [J]. Modern Electronics Technique, 35 (12), 101-106.

[13] Chen, W.B., Gong, D.S. 2012. Informatization vendor evaluation model based on AHP entropy method. Modern Electronics Technique, 35 (12), 101-106.

[14] Zhe, X.L. 2001. Fundamentals of applied information theory[M]. Beijing : Tsinghua University Press.

[15] BCEPP. 2001. People's Republic of China national economic and Trade Commission.DL/T722 - 2000 transformer oil dissolved gas analysis and judgment guideline [S]. Beijing: China Electric Power Press. 


\section{APPENDIXES}

This work was supported in part by Jilin Provincial Department of Educat ion "13th Five-Year Plan" (JJKH20180338KJ).

Science and Technology Project

\section{ABOUT THE AUTHORS}

Niu Guocheng (1977-), male, associate professor, doctoral student.

The main research is intelligent information processing, reliability analysis of complex systems. E-mail Niuguochengilin@163.com;
Corresponding author: Hu Zhen (1962-), female, professor, doctor The main research is intelligent information processing. E-mail: Huzhen21st@sina.com Hu Dongmei(1979-), female, professor, doctor The main research is intelligent information processing. E-mail: haitianme@163.com 